Вісник Дніпропетровського університету. Серія: геологія, географія. 2016. 24 (1), 98-101.

Vìsnik Dnìpropetrovs'kogo unìversitetu. Serî̀ geologiâ, geographîa

Dnipropetrovsk University Bulletin. Series geology, geography. 2016, 24 (1), 98-101.

doi: $10.15421 / 111614$

http://geology-dnu.dp.ua

УДК $624.131(477)$

\title{
Опыт прогноза деформаций просадки массива методами индуктивного моделирования
}

\author{
Т. П. Мокрицкая, В. Г. Батырь
}

Днепропетровский национальный университет имени Олеся Гончара, Днепропетровск, Украина, e-mail: mtatjana@bk.ru

Создание моделей геологической среды является актуальной задачей при решении проблем управления, мониторинга. Особую актуальность приобретает эта проблема на застроенных территориях, на территориях городов. Использование классических методов стохастического анализа для описания динамики компонентов среды, в частности, свойств грунтов, возможно в исключительных случаях. Методы индуктивного моделирования, в частности, методы группового учета аргументов и нейронных сетей, позволяют решить задачи прогноза на неполных и нерегулярных данных о состоянии сложной системы. Объектом изучения является массив просадочных грунтов в зоне влияния правобережной части г. Днепропетровска, сложенный причерноморским, дофиновским и бугским горизонтами лессовых грунтов. Плотность источников техногенного влияния велика, что приводит к развитию просадочных деформаций. Применялись методы математического, индуктивного и картографического моделирования для решения прогнозных задач о величине просадки.

Ключевые слова: моделирование, просадочный грунт, прогноз, лессы.

\section{Experience forecast strain drawdown array of inductive modeling techniques}

\author{
T. P. Mokritskaya, V. G. Batyr \\ Oles Honchar Dnepropetrovsk National University, Dnepropetrovsk, Ukraine, e-mail: mtatjana@,bk.ru
}

The article describes the experience of subsidence prediction of deformations of the array using the methods of inductive modeling. Inductive modeling methods, in particular methods of group account of arguments and neural networks can solve the problem of the forecast for the incomplete and irregular data on the state of a complex system. To solve the problem in the article involved the program trial - versions of Surfer, STATISTICA and authoring program Koryashkinoy L.S. In the course of solving the problem was carried out construction of spatial models of environment and its components (relief surfaces and capacities of individual horizons in the volume of the aeration zone, the surface level of underground water); models of behavior; predictive models subsidence. Construction of spatial models is performed in a scale of 1:25 000, in the conventional coordinate system, in an environment «Surfer». The data on the properties of the horizons of the zone of aeration were studied by statistical, correlation and regression types of stochastic analysis. The results of the primary analysis showed that the samples are heterogeneous and unbalanced by the values of skewness and kurtosis. Regression analysis showed that the use of stepwise regression method does not provide a significant multiple regression model. To forecast the relative subsidence were built inductive model of the relative depth of the subsidence and indicators of physical condition. According to the forecast values of subsidence relative to the regular grid of reference points in the depth interval specified capacity of the aeration zone, calculated the value of the total drawdown in a natural, middle and status of the array. The spatial position of the zones of change of the total drawdown indicates the position of the zones with different values forecast and realized risk. As a conclusion of the article can be said that the application of inductive modeling allows you to forecast changes in the natural subsidence with increasing humidity as a result of changes in the status of ground array.

Key words: model, regression, drawdown, forecast

Введение. Создание моделей геологической среды является актуальной задачей при решении проблем управления, мониторинга геологической среды (Ivanov, 2001). Особую актуальность приобретает эта проблема на застроенных территориях, на территориях городов. Развитие и активизация неблагоприятных и опасных сопряженных инженерно-геологических процессов в зоне влияния локальных и региональных природно-техногенных систем определяются множеством факторов. Создание картографических 
моделей риска предполагает выполнение ряда последовательных операций: создания модели среды, моделей свойств элементов среды, анализ их изменений, определение вероятности реализации эрозионных, гравитационных, суффозионных и просадочных процессов и явлений. Специфичность инженерно-геологических данных заключается в их избирательности и неполноте, отсутствии временных рядов наблюдений достаточной длины. Использование классических методов стохастического анализа для описания динамики компонентов среды, в частности, свойств грунтов, возможно в исключительных случаях. Методы индуктивного моделирования, в частности, методы группового учета аргументов и нейронных сетей, позволяют решать задачи прогноза на неполных и нерегулярных данных о состоянии сложной системы (Shimelevich; Obornev, 2008).

Постановка задачи. Риск возникновения просадочных деформаций в зоне неполного водонасыщения, по существующим методикам, не является предметом оценок (Kaloshina; Ponomarev, 2007). Еще в работах А.К.Ларионова и др. (Larionov; Priklonskij; Anan'ev 1959), указывалось на необходимость учета этих деформаций при решении практических задач. Нами выполнено построение модели геодинамического риска, обусловленного просадками грунта в зоне аэрации при повышении влажности.

Объект изучения - массив просадочных грунтов в зоне влияния правобережной части г. Днепропетровска, сложенный причерноморским, дофиновским и бугским горизонтами лессовых грунтов и характеризующейся наибольшей плотностью застройки.

Предмет изучения - изменение просадочности при природных и техногенных нагрузках в зоне влияния локальной природно-техногенной системы из-за увеличения влажности.

Методы изучения - математическое индуктивное и картографическое моделирование. Привлекались программы trial-версии программ Surfer, STATISTICA и авторская программа Коряшкиной Л.С. (Mokrickaja; Korjashkina, 2013).

Фактический материал - результаты инженерногеологических исследований предприятий «Укрюжгеология» и Днепрогиинтиз, переданные авторам безвозмездно для научной обработки. Общее количество данных о значениях относительной просадочности на ступенях давления 0,05-0,3 МПа составило 690. Значения были определены в период 1976 - 2007 гг. по монолитам, отобранным из зоны аэрации изучаемой территории в соответствии с действующими методиками лабораторного определения просадочности грунтов.
Результаты исследований и их обсуждение. Для создания модели геодинамического риска просадочных деформаций в зоне влияния городской локальной природно-техногенной системы необходимо выполнение операций: построение пространственных моделей среды и ее компонентов (рельефа, поверхностей и мощностей отдельных горизонтов в объеме зоны аэрации, поверхности уровня залегания подземных вод); моделей свойств; прогнозных моделей просадочности. Построение пространственных моделей выполнялось в масштабе 1:25 000, в условной системе координат, в среде «Surfer». Выполнено построение цифровой модели рельефа, поверхностей подошвы причерноморского, дофиновского, бугского горизонтов и их мощностей. Построение карты залегания уровня подземных вод выполнено по состоянию на 2003 год. При построении поверхностей во всех случаях использовался метод интерполяции Krige (Kriging). Это наиболее популярный в обработке экспериментальных данных геостатистический метод (Silkin, 2008). При выполнении интерполяции возможно задавать границу территории произвольной конфигурации.В данной работе граница изучаемой территории приближенно соответствует историческому центру города. Цифровая модель рельефа была построена по результатам оцифровки фрагмента топографической карты масштаба 1:25000 в системе условных координат. Такая же система декартовых условных координат применялась для построения моделей поверхностей изучаемых горизонтов, глубины залегания уровня грунтовых вод, мощностей горизонтов и массива.

Для создания прогнозных моделей зависимости относительной просадочности от изменения состояния по влажности использована методология (Kaloshina, Ponomarev, 2007). Данные о свойствах горизонтов, входящих в зону аэрации, были изучены методами статистического, корреляционного и регрессионного видов стохастического анализа. Моделирование связи между значениями относительной просадочности на разных ступенях давления (выходные переменные) и аргументами (координаты, глубина, показатели состояния) выполнено в среде STATISTICA. Результаты первичного анализа показали, что выборки неоднородны и несимметричны по значениям асимметрии и эксцесса.Но корреляция с природной влажностью значений пределов пластичности, плотности частиц и плотности достаточно высока, коэффициенты корреляции в основном не опускаются ниже 0,41 д. ед.

Регрессионный анализ показал, что использование метода пошаговой регрессии не позволяет получить достоверные модели множественной регрессии. Для 
задания входных переменных при выполнении прогноза были построены модели парной регрессии между природной влажностью и другими показателями свойств грунтов.Теоретически, при росте влажности в зоне влияния локальной природно-техногенной системы, возможно изменениесостояния грунта от природной влажности до влажности на границе текучести. Применив трехчленную градацию, можно выделить три интервала значений грунтов зоны аэрации. Слабую, среднюю интенсивность изменения состояния массива можно задать как интервал, в границах которого влажность не превышает максимальное для данной стадии значение. Пороговые значения природной влажности составили0,181 и 0,217 д. ед.

Для прогноза относительной просадочности были построены индуктивные модели зависимости относительной просадочности от глубины и показателей физического состояния. Затем были заданы входные переменные для прогноза значений относительной просадочности в интервале глубин от 1 до 20 м. По прогнозным значениям относительной просадочности для регулярной сети опорных точек в интервалах глубин, заданных мощностью зоны аэрации, выполнен расчет значений суммарной просадки в природном, слабонарушенном и измененном состоянии массива. Пространственное положение зон изменения величины суммарной просадки указывает на положение зон с разной величиной прогнозного и реализованного риска. Зоны находятся

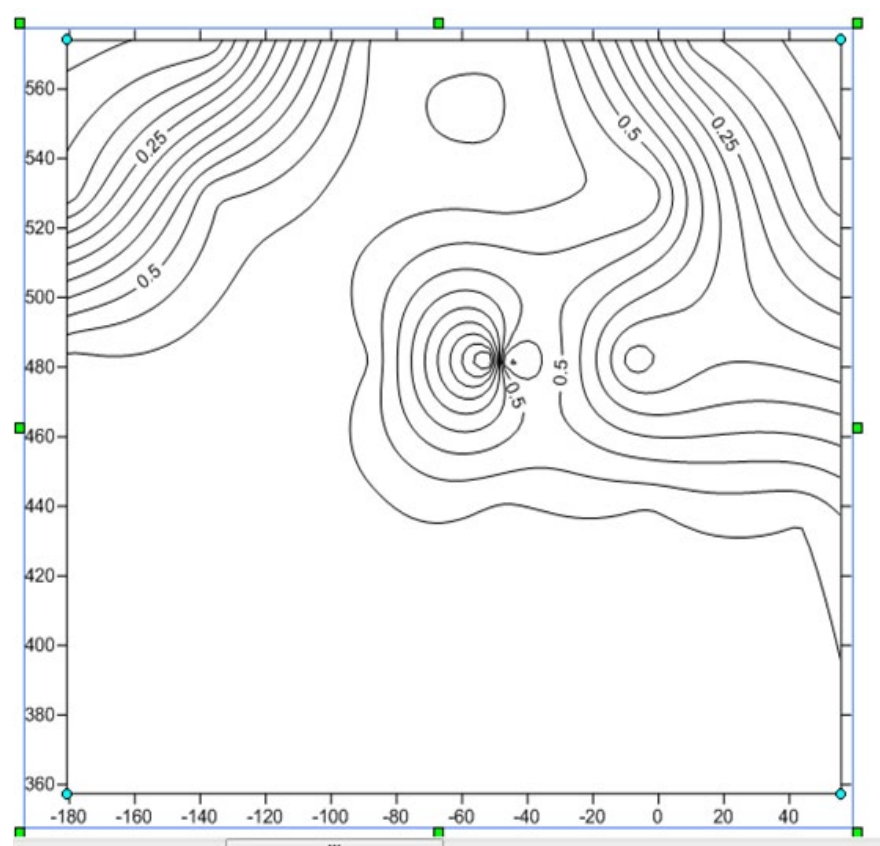

a) с применением операции вычитания поверхностей в программе «Surfer» (рис.).

\section{Выводы.}

- Применение методов индуктивного моделирования позволяет выполнить прогноз изменения просадочности при повышении природной влажности как результат изменения состояния грунтов массива;

- повышение влажности грунтов зоны аэрации приводит к реализации просадочных деформаций, величина которых сопоставима с критическими значениями суммарной осадки для типичных многоэтажных сооружений.

\section{Библиографические ссылки}

Ivanov, I. P., Trzhicinskij, Ju.B., 2001. Inzhenernaja geodinamika [Engineering geodynamics]. Sankt-Peterburg: Science. (in Russian).

Kaloshina, S.V., Ponomarev,A.B., 2007. Analiz sushhestvujushhih metodov rascheta osadok zdanij I naprjazhennodeformirovannogo sostojanija osnovanij [The analysis of existing methods for calculating the residue of buildings and stress-strain state grounds]. Vestnik Volg GASU, Ser.: Str-voiarhit., Vyp. 7 (26), 20 - 22 (in Russian). Larionov, A. K., Priklonskij, V. A., Anan'ev, V. P., 1959. Lessovye porody SSSR i ih stroitel'nye svojstva [Loess USSR and their construction properties]. M.: Gosgeoltehizdat. (in Russian).

Mokrickaja, T. P., Korjashkina, L. S., 2013. Faktory I modeli

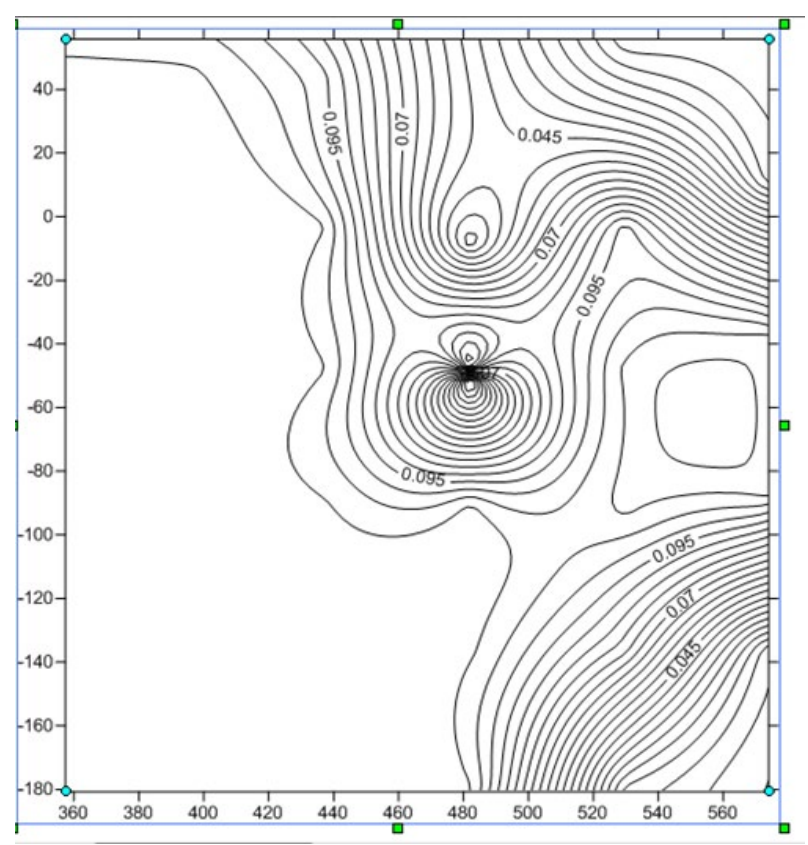

б)

Рис. Картографические модели реализованного риска при изменении природной влажности грунтов зоны аэрации: $a-$ в зоне влияния сооружений (при давлении $0,3 \mathrm{MПа);}$ $\sigma$ - за их пределами (при давлении $0,1 \mathrm{MПа)}$ 
degradacii prosadochnosti [Factors and model degradation subsidence]. Bulletin of National Mining University, 4, 5 - 12. (in Russian).

Mokrickaja, T.P., 2015. K voprosu o prognoze degradacii prosadochnyh svojstv gruntov [On the issue of degradation of forecast subsidence of soil properties]. Dnipropetr. Univ. Bull. Ser.: Geol., geogr., 23(1), 90 -94. doi: 10.15421/111512 (in Russian).

Shimelevich, M.I., Obornev, E.A., 2008. Nejrosetevoj metod magnitotelluricheskogo monitoring geojelektricheskih parametrov sredy na osnove nepolnyh dannyh [Neural network method of magnetotelluric monitoring geoelectric parameters of the medium on the basis of incomplete data]. Vestnik KRAUNC. Nauki o Zemle, issue 11, 171 - 176 (in Russian).

Silkin, K. Ju., 2008. Geoinformacionnaja sistema Golden Software Surfer 8 [Geographic Information System Golden Software Surfer 8]. Voronezh: Izdatel'skopoligraficheskij centr Voronezhskogo gosudarstvennogo universiteta. (in Russian). 